\title{
Orientación de meta de logro académico: un nuevo planteamiento
}

\author{
Christopher Was
}

Dpto. de Fundamentos Educativos y Servicios Especiales, Kent State University, Kent, Ohio

EE.UU.

cwas@kent.edu 


\section{Resumen}

Introducción: La distinción entre metas de dominio y de rendimiento ha sido el planteamiento teórico dominante a la hora de estudiar la orientación de meta durante las últimas tres décadas. Las investigaciones recientes empiezan a aportar evidencia de que sean necesarias más distinciones. También se sugiere que las creencias de los alumnos sobre la naturaleza de la inteligencia inciden en la clase de metas que éstos se plantean.

Método: A través del análisis factorial confirmatorio, este trabajo pretende incorporar las teorías implícitas sobre la inteligencia en una medida diseñada para captar las distinciones básicas entre las orientaciones de meta de dominio, de aproximación al rendimiento, de evitación del rendimiento, y de evitación de esfuerzo.

Resultados: Los resultados refrendan estas distinciones básicas y la inclusión de elementos de la inteligencia, pero también indican temas que requieren una investigación más extensa.

Conclusión: El trabajo presente sí aporta evidencia que es necesaria una línea de investigación que examine en más detalle el papel de las teorías implícitas sobre la inteligencia en la orientación de meta de logro. Estas percepciones pueden ser fundamentales en la forma de la que los alumnos abordan las tareas de logro en los ambientes académicos. El trabajo presente también aporta evidencia de que las metas de evitación de esfuerzo pueden ser más que una simple ausencia de la meta de logro: en cambio puede que realmente supongan una orientación de meta de logro digna de más estudio.

Keywords: orientación de meta, motivación, orientación al rendimiento, orientación al dominio, evitación de esfuerzo, teorías implícitas 